\title{
Correlation of Power Consumption of Double Impeller Based on Impeller Spacing in Laminar Region
}

\author{
Haruki Furukawa (D), Toshiki Kamiya, and Yoshihito Kato (iD \\ Department of Life Science and Applied Chemistry, Nagoya Institute of Technology, Gokiso-cho, Showa-ku, Nagoya, \\ Aichi 466-8555, Japan \\ Correspondence should be addressed to Haruki Furukawa; furukawa.haruki@nitech.ac.jp
}

Received 10 July 2019; Revised 9 September 2019; Accepted 14 September 2019; Published 16 October 2019

Academic Editor: Junwu Wang

Copyright (c) 2019 Haruki Furukawa et al. This is an open access article distributed under the Creative Commons Attribution License, which permits unrestricted use, distribution, and reproduction in any medium, provided the original work is properly cited.

\begin{abstract}
Power consumption is an important parameter for the design of mixing equipment. The aim of this study is to develop a new correlation of the power consumption of a double impeller. The effect of impeller spacing on the double-impeller flow pattern and power consumption was investigated in the laminar region. As a result, the effect of impeller spacing on the flow pattern was described based on the ratio of impeller spacing to the impeller blade height. Moreover, the power consumption of a double impeller could be correlated with the same ratio.
\end{abstract}

\section{Introduction}

Mixing is performed in many industries such as the chemical, food, pharmaceutical, and fermentation industries. In these industries, a high-aspect-ratio vessel is often used because of its limited footprint. The use of a single impeller in such vessels results in poor mixing performance. An unmixed region appears near the liquid surface and vessel bottom because the flow from the impeller underreaches the liquid surface and the vessel bottom. To improve mixing performance, multiple impellers are often used in high-aspect-ratio vessels [1]. Much research has been conducted to investigate the characteristics of multiple impellers. Yahata et al. [2] investigated the mixing regions of a double impeller and showed that the mixing regions above the upper impeller and below the lower impeller were constant. Komori and Murakami [3] compared the mixing efficiency and mixing time of single impellers with those of double impellers in a turbulent mixing vessel. They found that these factors were related to the flow patterns in the mixing vessel. Fasano et al. [4] studied the maximum allowed ratio of liquid height to tank diameter for a double impeller over a wide range of Reynolds numbers. Woziwodzki [5] studied the effect of unsteady rotating dual- turbine impellers on mixing of highly viscous Newtonian fluids. Several studies [6-9] employed computational fluid dynamics (CFD) to investigate the flow field in high-aspectratio vessels with multiple impellers. Arratia et al. [10] examined the mixing performance of multiple impellers in a shear-thinning fluid with yield stress. Xiao et al. [11] developed a new torus model of cavern formation in yield stress fluid for a single impeller and a double impeller using CFD.

Power consumption is one of the most important parameters in the design of mixing equipment because chemical engineers typically choose a motor based on power consumption. The power consumption of a double impeller in a turbulent region is twice that of a single impeller when the impeller spacing is 1 to 1.5 times the impeller diameter $[12,13]$. Hiraoka et al. [14] showed that the maximum power consumption of a double impeller in a turbulent region is almost twice that of a single impeller at a ratio of impeller spacing to liquid depth greater than 0.35 .

Double turbine impellers are used in gas-liquid mixing for chemical and biochemical processes. A turbine impeller is used to hold gas bubbles in gas-liquid mixing [7]. In these processes, the fluid often possesses non-Newtonian rheology, and the mixing is conducted in the laminar region. The 
power consumption in such non-Newtonian fluids is estimated using the Metzner-Otto method [15]. However, the power consumption characteristics of a double impeller in the laminar region of a Newtonian fluid have not been examined, and an estimation method for the power consumption of a double impeller has not yet been proposed. Therefore, it is impossible to estimate the power consumption in non-Newtonian fluids with the Meztner-Otto method.

In previous works $[12,13,16]$, the power consumption of a double impeller was expressed as a function of the ratio of impeller spacing to impeller diameter. However, this function is not applied to double impellers with a large blade width because the impeller blades interfere with each other when ratio of impeller spacing to impeller diameter is small. Moreover, secondary flow occurs above and below the impeller blades. Therefore, it is considered that the flow structure of impellers depends on the impeller blade width, even if the ratio of impeller spacing to impeller diameter is constant. In the present study, we measured the power consumption of a double impeller with various impeller spacings in a Newtonian fluid and clarified the effect of impeller spacing on the power consumption based on the flow field in a mixing vessel. A turbine impeller is used in this study because double turbine impellers are often used in gasliquid mixing with a high-aspect-ratio vessel. Moreover, we developed a new correlation regarding the power consumption of a double impeller based on the impeller spacing and impeller blade width. The experiment was conducted in the laminar region to estimate the power consumption in a non-Newtonian fluid in future work.

\section{Materials and Methods}

Figure 1 shows the experimental equipment. A transparent, flat-bottom cylindrical mixing vessel was used under the unbaffled condition. The inner diameter $D$ of the vessel was $0.185 \mathrm{~m}$. The mixing vessel was made with acrylic resin. The working fluid was a starch syrup solution (Kato Kagaku Co., Ltd.) with a density $\rho_{\mathrm{f}}$ of $1300-1380 \mathrm{~kg} / \mathrm{m}^{3}$ and a viscosity $\mu$ of 1.5-5.5 Pa.s. The liquid heights $H$ were $0.148,0.185,0.241$, and $0.278 \mathrm{~m}$, which correspond to $H / D=0.8,1.0,1.3$, and 1.5 , respectively. In this study, we used several kinds of turbine impellers, the dimensions of which are listed in Table 1. In all experiments, the upper and lower impellers were of the same type and size. The impellers were set symmetrically at the half level of the liquid height, as shown in Figure 1. The spacing between the upper and lower impellers, $L$, was in the range of $0.014-0.14 \mathrm{~m}$, which corresponds to $L / H=0.076-0.50$.

The flow field in the mixing vessel was obtained through particle image velocimetry (PIV) and expressed as streamlines. The PIV experiments were carried out with the aforementioned mixing equipment, which was placed inside a rectangular acrylic tank shown in Figure 1(c). The outer rectangular tank was filled with tap water to minimize optical refraction. Nylon particles with diameters $d_{\mathrm{p}}$ of $150-350 \mu \mathrm{m}$ and a density $\rho_{\mathrm{p}}$ of $1020 \mathrm{~kg} / \mathrm{m}^{3}$ were used as the passive tracer. The vertical cross section in the mixing vessel was illuminated using laser sheet light (Reliant 1000m, Laser Physics). The scattered light of the tracer particles was captured using a digital video camera (HDR-CX420, Sony Marketing Inc.). The captured images were analyzed using commercial flow analysis software FlowExpert2D2C (Katokoken Co., Ltd.). In this study, the right-hand side of the vertical plane was analyzed because the flow in the mixing vessel was symmetric with respect to the axial shaft.

Power consumption $P$ was obtained using the axial shaft torque method. The shaft torque $T$ was measured with a torque meter (ST-3000, Satake Chemical Equipment Mfg. Ltd.). The resolution of the torque meter was $0.0832 \mathrm{cN} \mathrm{m}$, and the smallest experimental torque in this study was $1.24 \mathrm{cNm}$. Therefore, it is considered that the torque measurement was accurate. The power consumption was calculated as

$$
P=2 \pi n T,
$$

where $n$ is the impeller rotation speed. The power consumption was described by the power number $N_{\mathrm{P}}$, which was defined as

$$
N_{\mathrm{P}}=\frac{P}{\rho_{\mathrm{f}} n^{3} d^{5}}
$$

where $d$ is the diameter of the impeller. The power number depends on the fluid density, fluid viscosity, impeller geometry, and vessel geometry.

\section{Results and Discussion}

3.1. Flow Field. We investigated the effect of impeller spacing on the flow field in the laminar region using PIV. The particle time constant $\tau_{0}$ of passive particle was calculated as [17]

$$
\tau_{0}=d_{\mathrm{p}}^{2} \frac{\rho_{\mathrm{p}}}{18 \mu} .
$$

The maximum particle time constant $\tau_{0, \max }$ of the passive particle used in this study was $8.35 \times 10^{-5} \mathrm{~s}$. The characteristic time of flow $T_{\mathrm{c}}$ was calculated as

$$
T_{\mathrm{c}}=\frac{L_{\mathrm{c}}}{U}
$$

where $L_{\mathrm{c}}$ is characteristic length and $U$ is characteristic velocity. The minimum characteristic time $T_{c, m i n}$ in this study was $1.21 \times 10^{-2} \mathrm{~s}$ when the impeller diameter and impeller blade tip velocity was adopted as $L_{\mathrm{c}}$ and $U$, respectively. Therefore, the passive particle was able to trace the flow in the stirred tank because of $\tau_{0 \text {, max }}<<T_{\mathrm{c} \text {,min }}$.

Figure 2 shows the streamlines acquired using PIV. At $L /$ $H=0.059(L / b=1)$, a pair of circulation loops was observed above and below the impellers. The double impeller functioned like a single impeller with twice the blade height at $L /$ $H=0.059(L / b=1)$. The pumping flow from each impeller interferes with the decreased impeller spacing. Therefore, a circulation loop between the impellers was not observed. Finally, at $L / H=0.3(L / b=5.0)$, a pair of circulation loops was observed above and below each of the impellers. The impellers function independently at $L / H \geq 0.3$. 


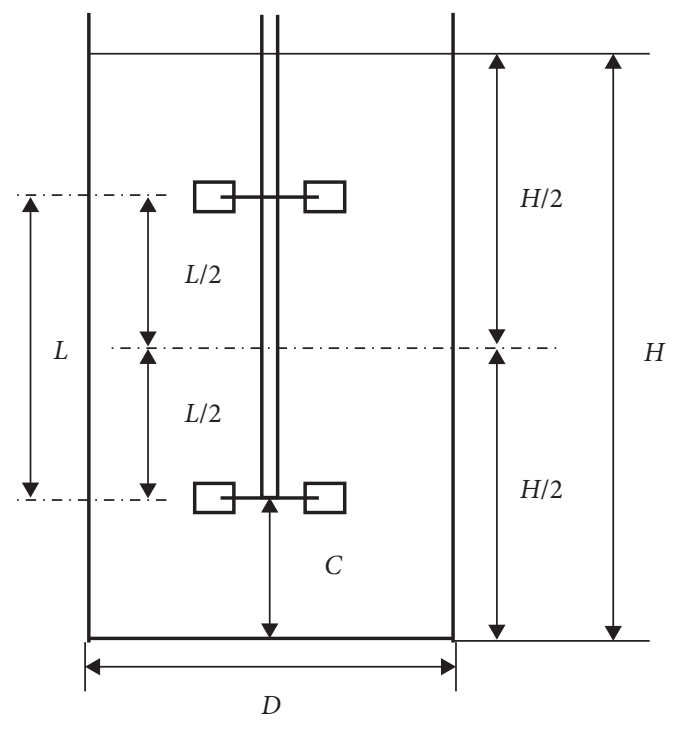

(a)
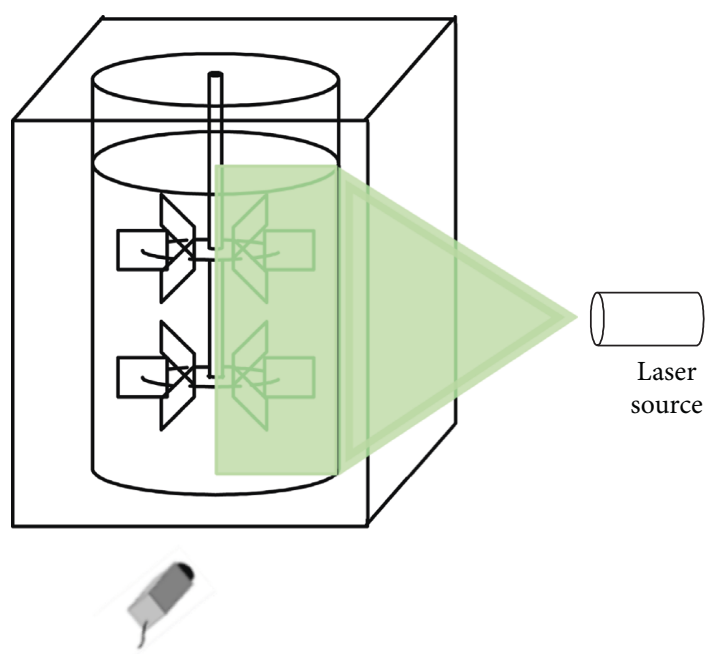

Digital video camera

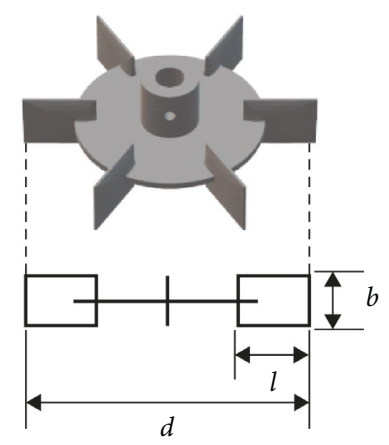

(b)

(c)

Figure 1: Experimental equipment. (a) Mixing vessel. (b) Turbine impeller. (c) Schematic illustration of PIV experiment.

TABLE 1: Specifications of the impellers.

\begin{tabular}{lccccc}
\hline Impeller no. & $d / D(-)$ & $b / d(-)$ & $l / d(-)$ & $d_{\mathrm{C}} / d(-)$ & $n_{\mathrm{P}}(-)$ \\
\hline 1 & 0.54 & 0.20 & 0.25 & 0.65 & 6 \\
2 & 0.43 & 0.20 & 0.25 & 0.65 & 6 \\
3 & 0.43 & 0.30 & 0.25 & 0.79 & 6 \\
4 & 0.43 & 0.40 & 0.25 & 0.79 & 6 \\
5 & 0.39 & 0.20 & 0.25 & 0.69 & 6 \\
\hline
\end{tabular}

Figure 3 shows the effect of the impeller blade height on the flow pattern between the impellers. Figures 3(a) and 3(b) show the streamlines with $b / d=0.3$ and 0.4 , respectively. In Figure 2, which shows the streamlines with $b / d=0.2$, the impeller functions independently at $L / H=0.30$. However, the impellers with $b / d=0.3$ or 0.4 do not function independently at $L / H=0.30$. We focused on the ratio of

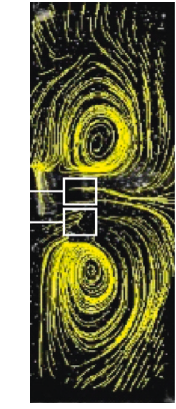

$L / H=0.059$

$L / b=1.0$

$L / d=0.20$

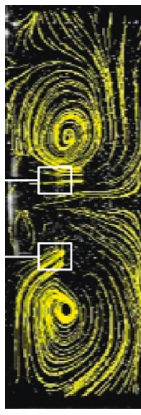

0.20

3.4

0.68

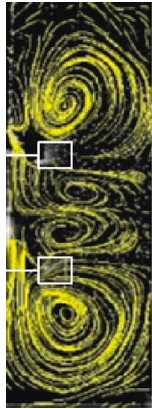

0.30

5.0

1.0

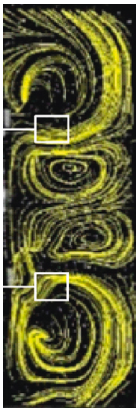

0.40

6.8

1.4
Figure 2: Streamlines with different impeller spacings at $\mathrm{Re}=8$ $(d / D=0.43, b / d=0.20, H / D=1.5)$. 


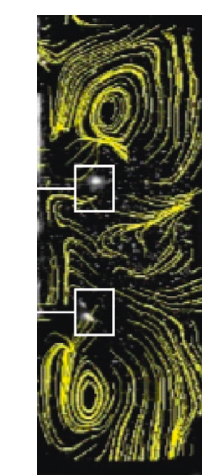

$L / H=0.30$

$L / b=3.4$

$L / d=1.0$

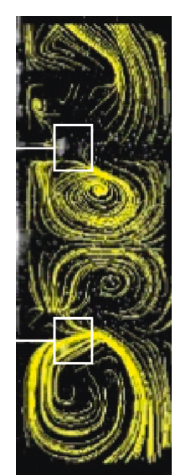

0.44

5.0

1.5

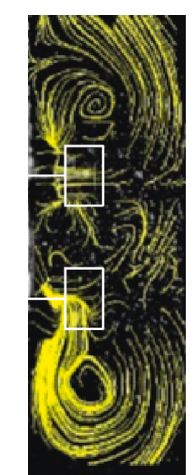

$L / H=0.30$

$L / b=2.5$

$L / d=1.0$

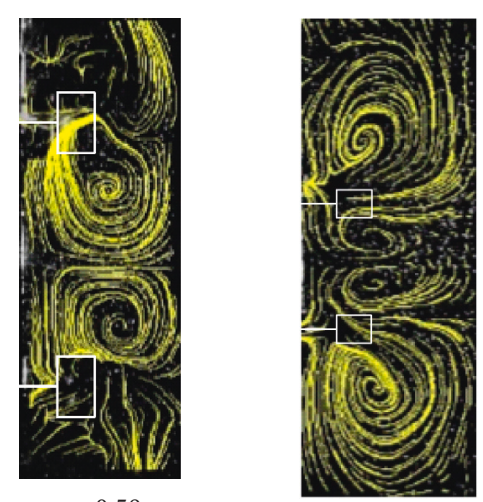

0.58

5.0

2.0

(b)

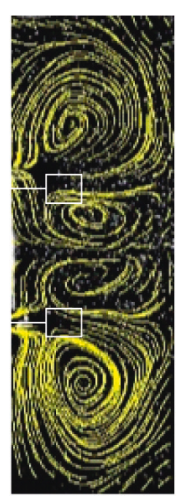

0.3

5.7

1.1

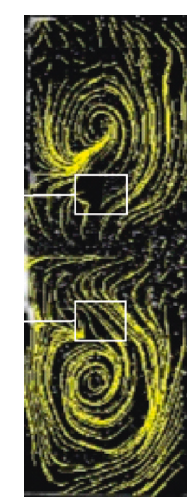

$L / H=0.30$

$L / b=4.0$

$L / d=0.80$

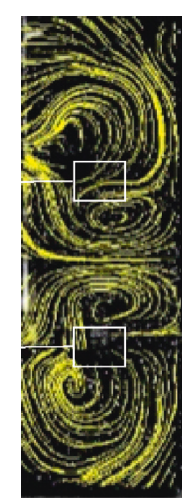

0.37

5.0

1.0

(a)

(b)

FIgURE 4: Effect of impeller diameter on flow between impellers at $\operatorname{Re}=8(\mathrm{~b} / \mathrm{d}=0.2, H / D=1.5)$. (a) $d=0.072 \mathrm{~m}$. (b) $d=0.10 \mathrm{~m}$.

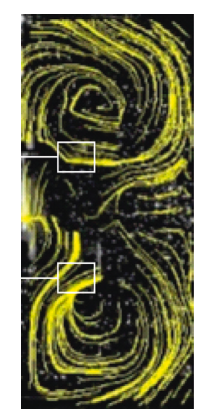

$L / H=0.30$

$L / b=3.4$

$L / d=0.69$

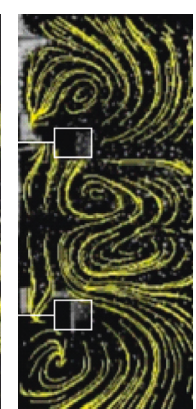

0.44

5.0

1.0

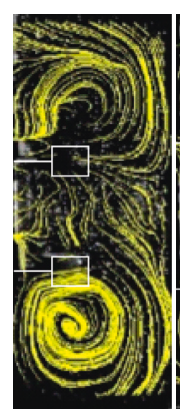

$L / H=0.30$

$L / b=4.5$

$L / d=0.9$

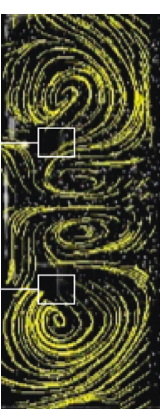

0.33

5.0

1.0

(a)

(b)

Figure 5: Effect of liquid depth on flow between impellers at $\mathrm{Re}=8$ ( $d / D=0.43, b / d=0.2)$. (a) $H / D=1.0$. (b) $H / D=1.3$.

that power consumption in the laminar region is independent of the distance between the impeller and the off bottom. Therefore, the power consumption of a double impeller is only dependent on $L / b$ at each distance.

Figure 8 shows the result of the correlation of power consumption of the double impeller. The $y$-axis is the ratio of $N_{\mathrm{P}} \cdot \operatorname{Re}$ for a double impeller, $\left(N_{\mathrm{P}} \cdot \operatorname{Re}\right)_{\text {double impeller, to the }}$ $N_{\mathrm{P}} \cdot$ Re for a double impeller at $L / b=1.0,\left(N_{\mathrm{P}} \cdot \mathrm{Re}\right)_{L / b=1}$, because $N_{\mathrm{P}} \cdot \mathrm{Re}$ is constant in the laminar region. The solid line in Figure 8 represents the correlation, which is expressed as

$$
\frac{\left(N_{\mathrm{P}} \cdot \operatorname{Re}\right)_{\text {double }}}{\left(N_{\mathrm{P}} \cdot \operatorname{Re}\right)_{L / b=1}}=\left(\frac{L}{b}\right)^{0.20}, \quad 1 \leq L / b<5 .
$$

The dashed line in Figure 8 represents the relative error, which is $\pm 5 \%$. This correlation is in good agreement with the experimental values. $\left(N_{\mathrm{P}} \cdot \mathrm{Re}\right)_{L / b=1}$ is equal to that of a single impeller with a blade height twice the blade height of a double impeller. The $N_{\mathrm{P}} \cdot$ Re for a single impeller can be calculated from the correlation developed by many fluid height above the upper impeller have no effect on
power consumption in the laminar region. This result is in good agreement with our previous work [18], which shows upper impeller. According to Figure 7, the distance between the lower impeller and the off bottom and, consequently, the fluid height above the upper impeller have no effect on good agreenent with our 


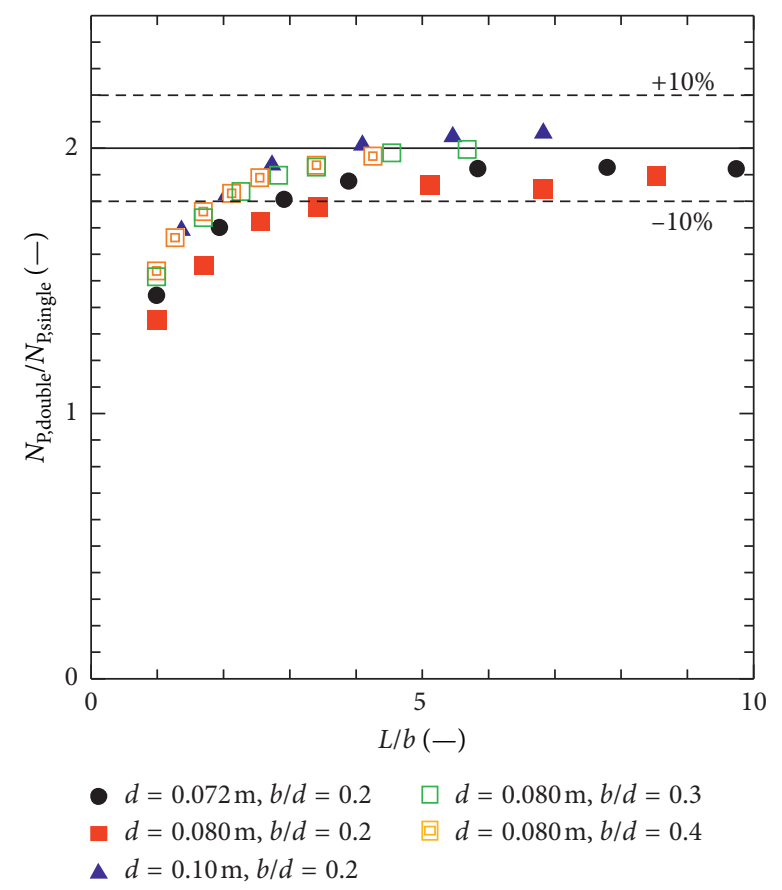

FIGURE 6: Effect of impeller spacing on power number at $\mathrm{Re}=6$. The solid line represents the constant value 2 . The dotted lines represent the relative error of $\pm 10 \%$ from the solid line.

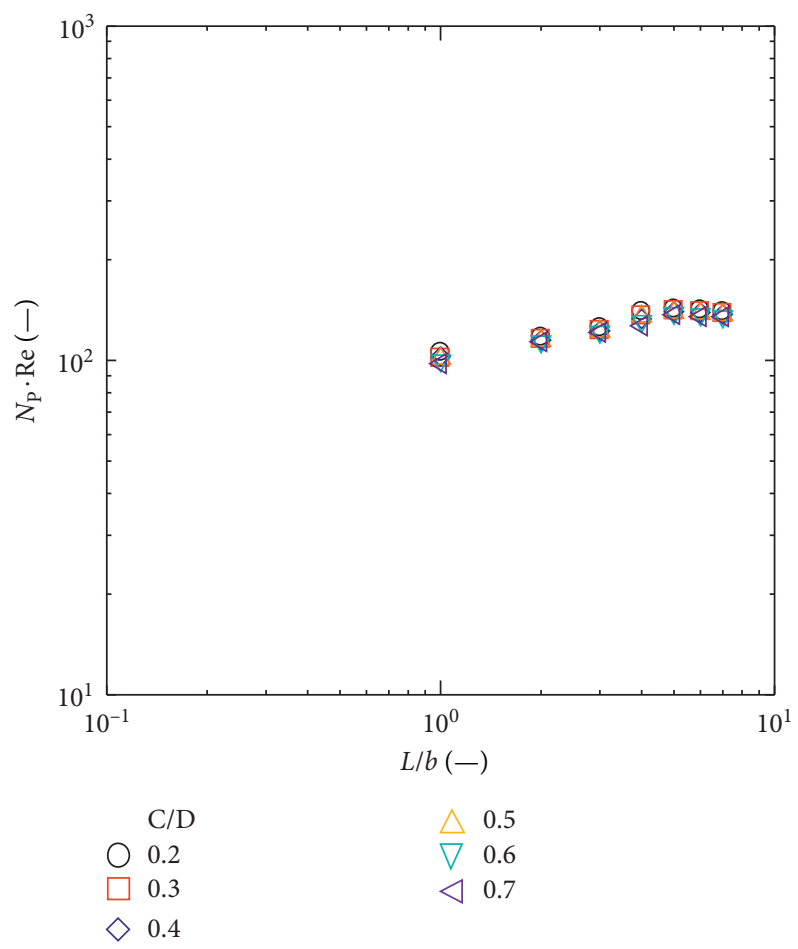

FIGURE 7: Effect of distance between the lower impeller and the off bottom on power consumption $(d / D=0.43, b / d=0.2)$.

researchers [19-21]. For example, the correlation developed by Nagata et al. [20] can be expressed as

$$
N_{\mathrm{P}}=\frac{A}{\operatorname{Re}}+B\left(\frac{10^{3}+1.2 \mathrm{Re}^{0.66}}{10^{3}+3.2 \mathrm{Re}^{0.66}}\right)^{p}\left(\frac{H}{D}\right)^{(0.35+b / D)}(\sin \theta)^{1.2} \text {, }
$$

$$
A=14+(b / D)\left\{670(d / D-0.6)^{2}+185\right\}
$$

$$
B=10^{\left\{1.3-4(b / D-0.5)^{2}-1.14(d / D)\right\}}
$$

$$
p=1.1+4(b / D)-2.5(d / D-0.5)^{2}-7(b / D)^{4} .
$$




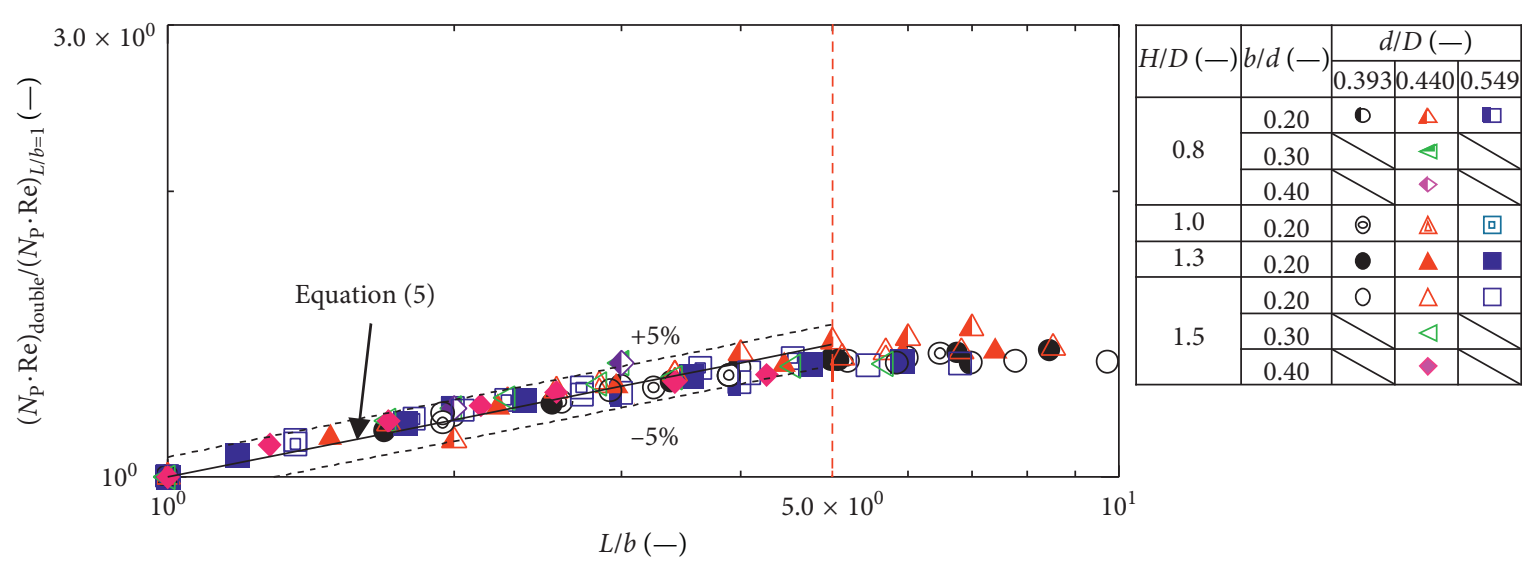

FIgURE 8: Correlation of power consumption for a double impeller. The solid line represents equation (5). The dotted lines represent the relative error of $\pm 5 \%$ from equation (5). The red dashed line represents $L / b=5.0$.

Therefore, the power consumption for a double impeller at an arbitrary impeller spacing in the range $1 \leq L / b<5$ can be estimated by equation (5), and the power consumption for an impeller spacing of $5 \leq L / b$ can be estimated as twice that of a single impeller with the same size.

\section{Conclusion}

In this study, the effect of impeller spacing between impellers on the flow pattern and power consumption was investigated using turbine impellers under the laminar region. We first investigated the effect of impeller spacing on the flow pattern by using PIV. The change of flow pattern is described based on the ratio of impeller spacing between impellers to the impeller blade height, $L / b$. At $L / b=1.0$, the double impeller functions like a single impeller. The flow between impellers interacts in the range $1<L / b<5$. Each of the double impeller functions independently in the range $5 \leq L / b$.

The power consumption of a double impeller in the range $1 \leq L / b<5$ can be simply correlated by equation (5), and that of a double impeller in the range $5<L / b$ is twice that of a single impeller of the same size. The power consumption is closely related to the flow pattern. A chemical engineer can estimate the power consumption of a double impeller by using this developed correlation.

\section{Nomenclature}

A: $\quad$ Proportional constant used in equation (6) (-)

$b$ : Impeller blade height $(\mathrm{m})$

B: $\quad$ Proportional constant used in equation (6) (-)

$d$ : Impeller diameter $(\mathrm{m})$

$d_{\mathrm{c}}: \quad$ Impeller disc diameter $(\mathrm{m})$

$d_{\mathrm{p}}: \quad$ Tracer particle diameter $(\mathrm{m})$

$D$ : $\quad$ Vessel inner diameter $(\mathrm{m})$

$H: \quad$ Liquid depth $(\mathrm{m})$

$l: \quad$ Impeller width $(\mathrm{m})$

$L: \quad$ Impeller spacing $(\mathrm{m})$

$L_{\mathrm{c}}: \quad$ Characteristic length $(\mathrm{m})$

$n$ : $\quad$ Impeller rotational speed $(1 / \mathrm{s})$
$n_{\mathrm{P}}: \quad$ Number of blades $(-)$

$N_{\mathrm{p}}: \quad$ Power number $\left(=\mathrm{P} / \rho_{\mathrm{f}} n^{3} d^{5}\right)(-)$

$p: \quad$ Exponent used in equation (6) (-)

$P: \quad$ Power consumption (W)

Re: $\quad$ Reynolds number $\left(=\rho_{\mathrm{f}} n d^{2} / \mu\right)(-)$

$T: \quad$ Shaft torque $(\mathrm{N} \cdot \mathrm{m})$

$T_{c}$ : $\quad$ Characteristic time of flow (s)

$T_{\mathrm{c}, \text { min }}$ : Minimum characteristic time of flow (s)

$u_{\mathrm{ps}}: \quad$ Settling velocity $(\mathrm{m} / \mathrm{s})$

U: $\quad$ Characteristic velocity $(\mathrm{m} / \mathrm{s})$

Greek letters

$\rho_{\mathrm{f}}: \quad$ Fluid density $\left(\mathrm{kg} / \mathrm{m}^{3}\right)$

$\rho_{\mathrm{p}}: \quad$ Tracer particle density $\left(\mathrm{kg} / \mathrm{m}^{3}\right)$

$\theta: \quad$ Angle of blades to the horizontal plane (-)

$\mu$ : $\quad$ Fluid viscosity (Pa.s)

$\tau_{0}$ : $\quad$ Particle time constant of passive tracer (s)

$\tau_{0, \text { max }}:$ Maximum particle time constant of passive tracer $(\mathrm{s})$.

\section{Data Availability}

The experimental data used to support the finding of this study are included within the article.

\section{Conflicts of Interest}

The authors declare that there are no conflicts of interest regarding the publication of this paper.

\section{Acknowledgments}

The present study was supported by Nagoya Institute of Technology.

\section{References}

[1] R. Petricek, L. Labik, T. Moucha, F. J. Rejl, L. Valenz, and J. Haidl, "Volumetric mass transfer coefficient in fermenter: scale-up study in viscous liquids," Chemical Engineering Technology, vol. 40, no. 5, pp. 878-888, 2017.

[2] T. Yahata, F. Komatsu, M. Akiyoshi, and K. Ando, "Effect of adjacent impeller on mixing region of impeller in stirred 
vessel with two stage turbine impellers," Kagaku Kogaku Ronbunshu, vol. 13, no. 5, pp. 691-693, 1987.

[3] S. Komori and Y. Murakami, "Turbulent mixing in baffled stirred tanks with vertical-blade impellers," AIChE Journal, vol. 34, no. 6, pp. 932-937, 1988.

[4] J. B. Fasano, A. Bakker, and W. R. Penney, "Advanced impeller geometry boosts liquid agitation," Chemical Engineering, vol. 101, pp. 110-116, 1994.

[5] S. Woziwodzki, "Mixing of viscous Newtonian fluids in a vessel equipped with steady and unsteady rotating dualturbine impellers," Chemical Engineering Research and Design, vol. 92, pp. 435-446, 2014.

[6] C. Haringa, R. Vandewijer, and R. F. Mudde, "Inter-compartment interaction in multi-impeller mixing: Part I. Experiments and multiple reference frame CFD," Chemical Engineering Research and Design, vol. 136, pp. 870-885, 2018.

[7] M. Taghavi, R. Zadghaffari, J. Moghaddas, and Y. Moghaddas, "Experimental and CFD investigation of power consumption in a dual Rushton turbine stirred tank," Chemical Engineering Research and Design, vol. 89, no. 3, pp. 280-290, 2011.

[8] K. Takata, H. Ito, M. Kikuchi, and Y. Okamoto, "Flow and mixing characteristics in a stirred tank with dual wide paddles," Kagaku Kogaku Ronbunshu, vol. 25, no. 2, pp. 253-258, 1999.

[9] H. Wu, S. Shu, N. Yang, G. Lian, S. Zhu, and M. Liu, "Modeling of power characteristics for multistage rotor-stator mixers of shear-thinning fluids," Chemical Engineering Science, vol. 117, no. 27, pp. 173-182, 2014.

[10] P. E. Arratia, J. Kukura, J. Lacombe, and F. J. Muzzio, "Mixing of shear-thinning fluids with yield stress in stirred tanks," AIChE Journal, vol. 52, no. 7, pp. 2310-2322, 2006.

[11] Q. Xiao, N. Yang, J. Zhu, and L. Guo, "Modeling of cavern formation in yield stress fluids in stirred tanks," AIChE Journal, vol. 60, no. 8, pp. 3057-3070, 2014.

[12] M. Nishikawa, K. Ashiwake, N. Hahimoto, and S. Nagata, "Effect of impeller clearance on power consumption by multi-stage impellers," Kagaku Kogaku Ronbunshu, vol. 2, no. 4, pp. 426-431, 1976.

[13] R. L. Bates, P. L. Fondy, and R. R. Corpstein, "An examination of some geometric parameters of impeller power," Industrial and Engineering Chemistry Process Design and Development, vol. 2, no. 4, pp. 310-314, 1963.

[14] S. Hiraoka, Y. Kato, Y. Tada, N. Ozaki, Y. Murakami, and Y.S. Lee, "Power consumption and mixing time in an agitated vessel with double impeller," Transactions of the Institution of Chemical Engineers, vol. 79, no. 8, pp. 805-810, 2001.

[15] A. B. Metzner and R. E. Otto, "Agitation of non-Newtonian fluids," AIChE Journal, vol. 3, no. 1, pp. 3-10, 1957.

[16] J. Y. Oldshue, Fluid Mixing Technology, McGraw-Hill, New York, NY, USA, 1st edition, 1983.

[17] R. J. Adrian and J. Westerwel, Particle Image Velocimetry, Cambridge University Press, New York, NY, USA, 2011.

[18] H. Furukawa, Y. Kato, Y. Tada, S. T. Koh, and Y. S. Lee, "Dependence of Reynolds number for power consumption change on paddle impeller position," Kagaku Kogaku Ronbunshu, vol. 38, no. 3, pp. 144-147, 2012.

[19] J. H. Rushton, E. W. Costich, and H. J. Everett, "Power characteristics of mixing impellers part 1," Chemical Engineering Progress, vol. 46, pp. 395-404, 1950.

[20] S. Nagata, K. Yamamoto, T. Yokoyama, and S. Shiga, "Empirical equation for the power requirement of mixing impellers, having a wide range of applicability," Kagaku Kogaku, vol. 21, no. 11, pp. 708-715, 1957.

[21] N. Kamei, S. Hiraoka, Y. Kato et al., "Power correlation for paddle impellers in spherical and cylindrical agitated vessels," Kagaku Kogaku Ronbunshu, vol. 21, no. 1, pp. 41-48, 1995. 


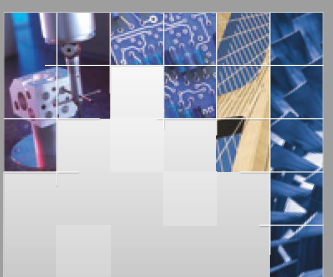

\section{Enfincering}
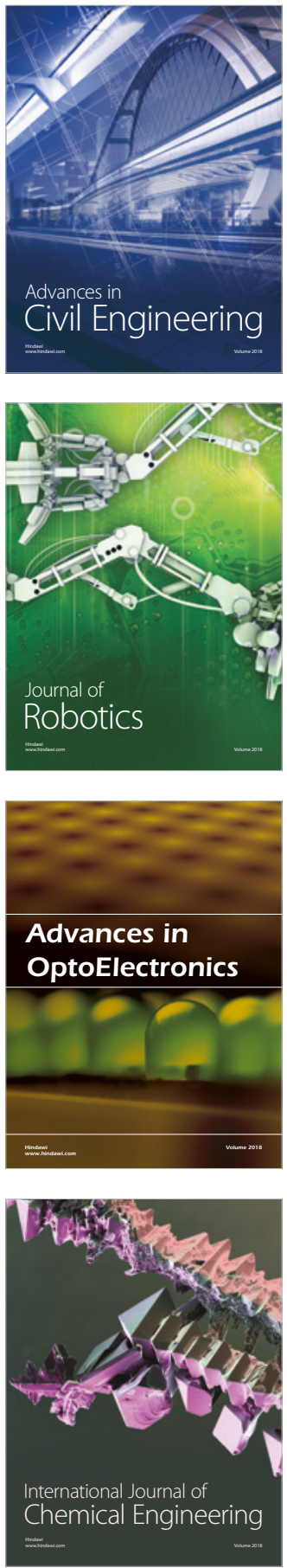

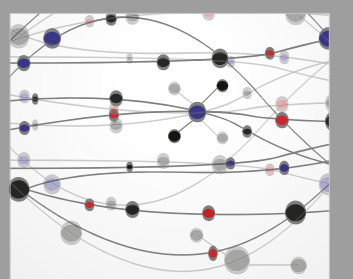

\section{Rotating \\ Machinery}

The Scientific World Journal

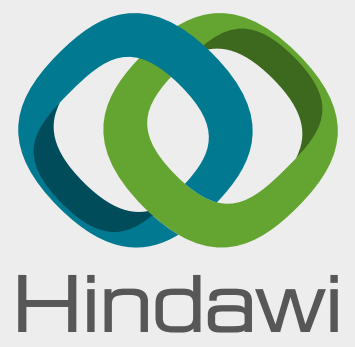

Submit your manuscripts at

www.hindawi.com
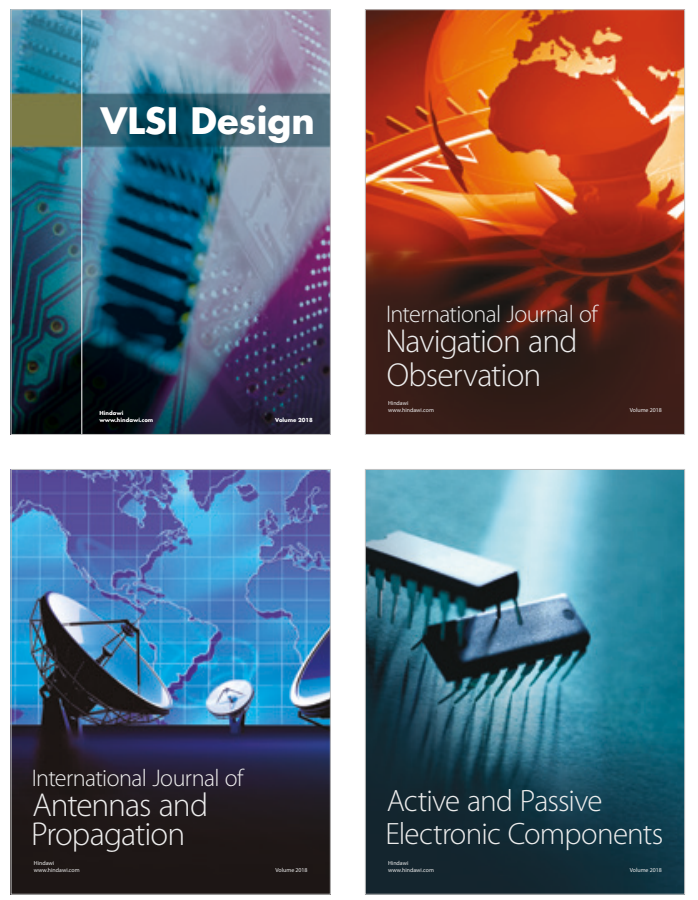
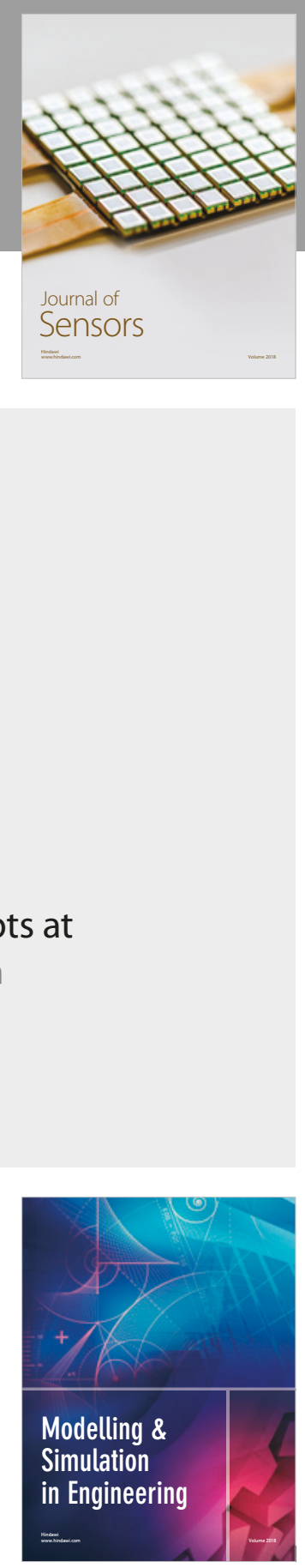

\section{Advances \\ Multimedia}
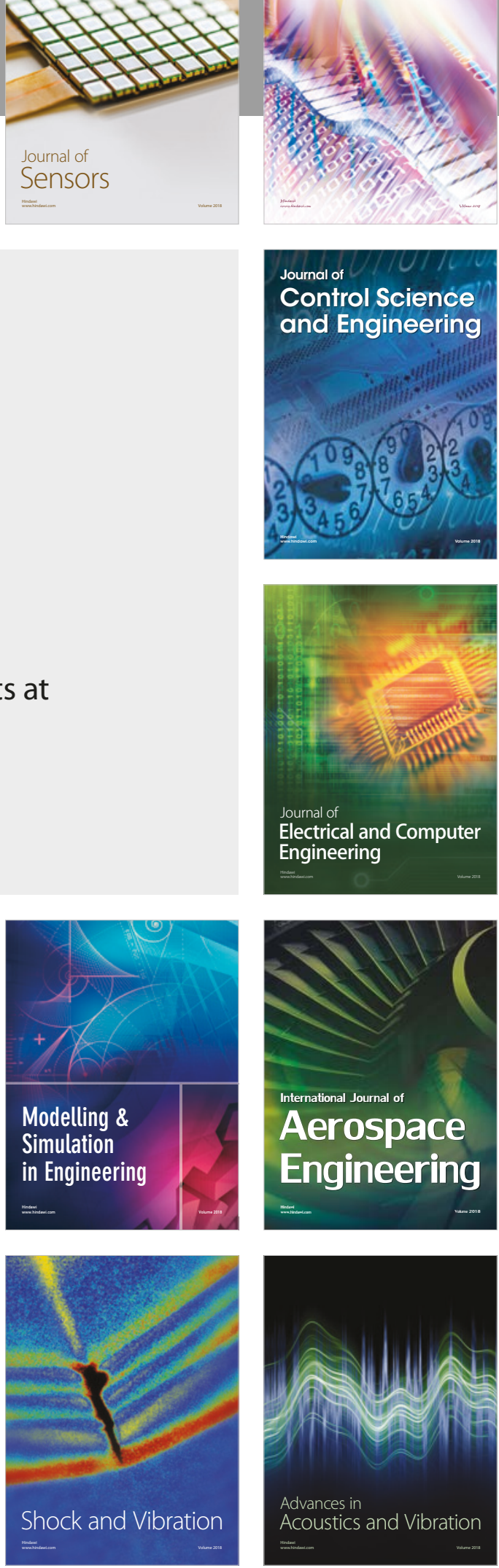